\title{
A brief overview of the evolution and trends in maintenance
}

\author{
Eugen Pămîntaş ${ }^{1 *}$, and Felicia veronica Banciu $^{1}$ \\ ${ }^{1}$ Politehnica University of Timişoara, Materials and manufacturing d Department, 300222, Timişoara, Timiş, Romania
}

\begin{abstract}
From the mistakes of industrial past, from the needs of today's manufacturing industry, from the knowledge accumulations of theoreticians, researchers and practitioners in the field presented in scientifical papers and reviews, the future directions of $\mathrm{R} \& \mathrm{D}$ in the field of maintenance were outlined in this paper.
\end{abstract}

\section{Introduction}

For the production of goods the industry has widely used different processes that have known various classifications. For example, the simplest classification of manufacturing processes is made by Swift and Booker [1]: casting, cutting, forming and manufacturing, while Kalpakjian and Schmid [2] provide a more comprehensive classification in six subcategories of casting, machining and finishing, joining, sheet metal, polymer processing and deformation processes. It is noted that both traditional classifications have certain limitations on the identification of newly developed technologies (e.g., rapid prototyping, die casting and injection molding) [3]. Regardless of the category they belong to, machine tools, equipments or machinery have been stepping up with technological advances but also with their needs and especially the scientific knowledge they have embedded. Regardless of their degree of complexity, throughout their technological evolution, all machines and installations, regardless of the type of drive and the working environment, needed repair work due to natural damage or the effect of work wear.

Technological developments and the current economic context have created major changes in maintenance systems. These developments need to be analyzed to determine their contributions and their negative effects. For this it is necessary to know the new achievements in the field, evaluation techniques and methods of controlling their effects. An ample bibliographic synthesis limited to a specific topic within a particular manufacturing area provided by $[4,5]$ has shown that:

- As new concepts are introduced into the manufacturing industry, the research community is trying to identify future frontiers of research;

- As new manufacturing paradigms are revealed, the component subsystems of the manufacturing systems should be carefully re-examined to explore how new technologies influence the current infrastructure;

- To date, it is noted that there are relatively few advanced manufacturing concepts syntheses published;

- In the literature reviewed, manufacturing systems are classified differently according to their evolution and therefore, it is a real challenge to try to establish a type or a subsequent category of a manufacturing system. It is therefore necessary to develop an appropriate taxonomy to investigate the various aspects of its production and maintenance systems. Most researchers in the field are concerned with studying new advanced manufacturing trends that are already developing and less with systematizing the knowledge gained in the field.

- few studies have addressed the negative effects that ICT may induce in a manufacturing company through changes in labor patterns and due to their poor integration and utilization.

This paper presents a view of maintenance, analyzing a wide range of publications covering many sub-areas and topics. Some of the arguments that lead the industry to take new initiatives in enterprises, processes, production systems and equipment levels are also underlined.

The purpose of this paper is to report the state of the art of maintenance related to structural changes of machine tools by presenting a clinical review of the literature currently available on the subject.

The paper aims to bring attention to the concepts of selflearning, the summative analysis of becoming so far, the emphasis on previous features and the pre-configuration of the directions of the future as well as examples of new approaches to the self-maintenance concept along with future research challenges..

\section{From simple repair to maintenance}

It is widely known that industrial maintenance is a knowledge intensive field based on different disciplines covering a wide range of technical sciences involved in the various technologies included in modern industrial equipment. Therefore, until recently, the complexity of the equipment and the need to have a knowledge bag corresponding to a very large area of science and technology was the main limitation of substantial improvements to the discipline of maintenance. In fact, innovative advances in support technologies are needed to enable maintenance engineering to fully develop its potential. In this respect, new ICT-based and microelectronic technologies - such as intelligent data

\footnotetext{
* Corresponding author: eugen.pamintas@upt.ro
} 
capture, advanced viewing, wireless, IoT (internet of things) and intelligent sensors - provide maintenance with the environmental intelligence needed to renew the way forward maintenance [6].

The evolution of the field to which the task of preserving machinery and installations has come to be seen, in a general picture, as having three well-defined areas (see Fig. 1): management and management of activities (underground), workers maintenance and repair work (First Level) and Maintenance Intervention Objects (Workshop). The results of the company from the operation of machinery and installations are linked to the hopes of those who have their eyes and ears at every moment on how they "fight": the productive but also the related and support sector, the administrative management compartments but more chosen patronage.
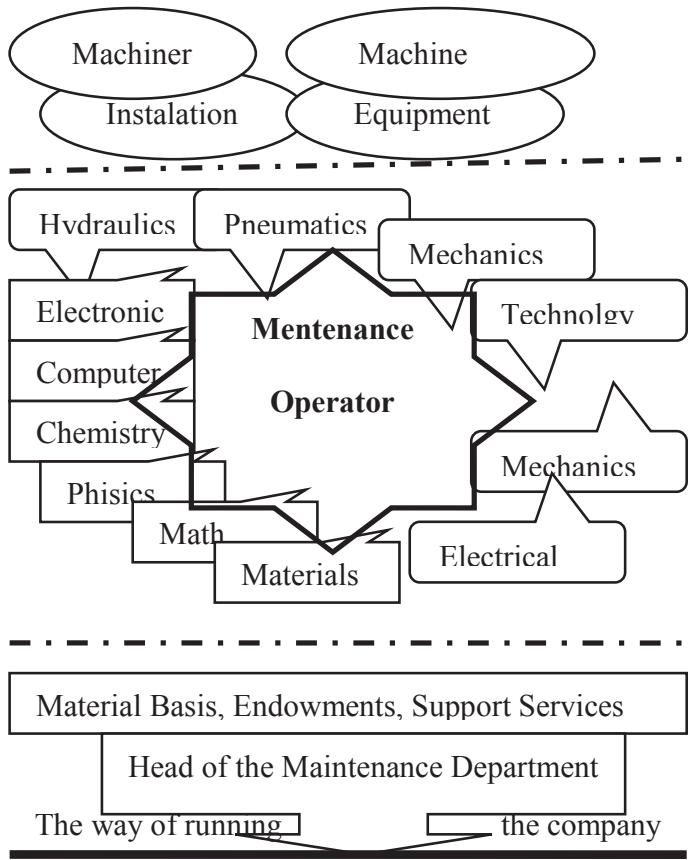

Fig. 1. General picture of maintenance field.

Regarding the first two aspects of the present study field evolution, the literature highlights several approaches that chronologically systematize the stages or ample and detailed the content. Under these circumstances, just to avoid hiatus in the logical development of the subject, we will continue to make a brief and narrative review of them.

The maintenance operator, the one who had to repair and re-install the fallen equipment, has accumulated constant knowledge, has acquired skills and has perfected his technique continuously. This happened until he has not dealt with the constructive and functional complexity of the subject of its activity. The need to carry out the tasks led to the transition from a worker to a team of workers. First, the team was made up of at least two operators of the same profession (say mechanic or electro-mechanical locks as examples) and then the team members got different qualifications. The path to the distinct specialization of operators in the work team has passed through the transient phase of cumulative qualifications, e.g. mechanic and welding or electromechanical and welding or electrician and electronics etc. Then he

continued with qualifications centred on the types of actuation and control (mechanical, electrical, hydropneumatic, electronics) and more rarely on machine type and their subassemblies (gearboxes, transport systems and tracks, frames and elements of the resistance structure, spindles etc.).

At the same time, there has also been a change in the role of the teams: intervention, maintenance and supervision, repairs, etc. and the coordination of the work of the teams has gone from the task of maintenance and repair to the maintenance department which, with the change of name, has also received new tasks: planning, management, monitoring, control, prediction, design and development strategies modernization, etc. Synthetically and schematically, the evolution of the maintenance domain in the manufacturing industry can be replayed by the schemes of Fig. 2

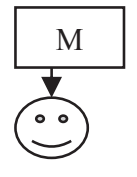

An operator, A qualification, A machine

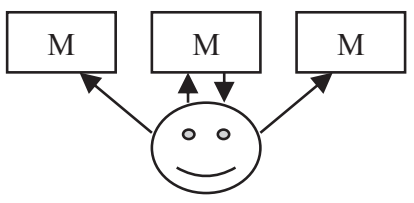

An operator, Two qualification, Several machines

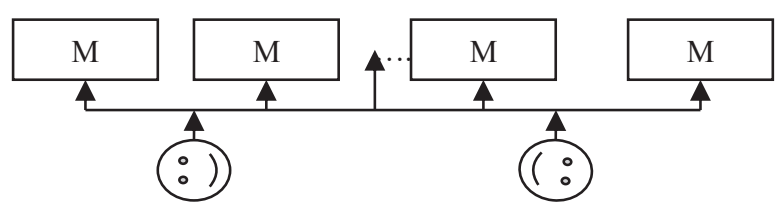

A team, Various poly-qualifications, Several machines

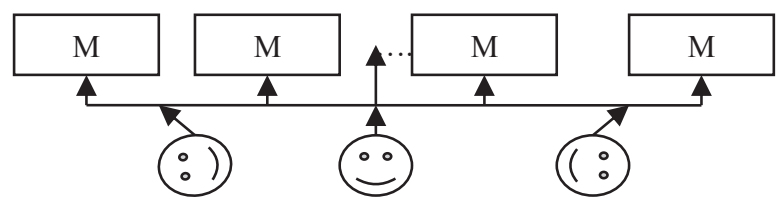

A team, Several specializations, More machines

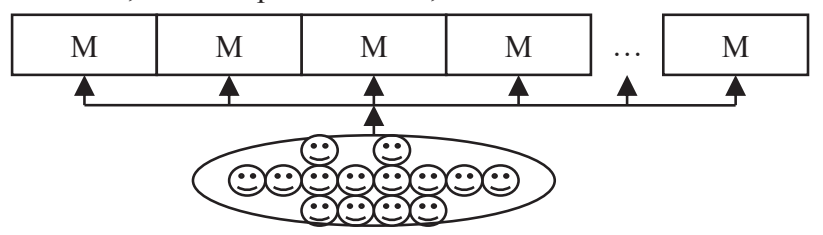

A department, Several teams with diverse specializations. An entire company

Fig. 2. Maintenance tasks in the manufacturing industry

The third area, the object of maintenance activity, will be given a wider attention in several respects, in order to argue the choice of the subject of the present paper and possible solutions for this.

\section{On the evolution of manufacturing machinery and equipment}

As machines and installations have increased their performance, the need to increase production flexibility, reduce energy consumption, increase operational safety, reduce to complete elimination of downtime and unplanned stops has increased the attention paid for their 
constructive-structural conception. Here are some remarkable results:

- to counteract the wear effect of the moving parts: antifriction alloys, oils and greases with superior and long-lasting properties, screws, slides and guides with rolling elements, etc.;

- for shortening the kinematics drive chains: replacement of gearboxes with electric speed changers;

- for monitoring the technical condition of the machine: built-in sensors for measuring of temperature, vibration amplitude and frequency, working fluid pressure, etc.

If we take into account only how the machine designers have responded over time to the requirements imposed by the need for maintenance, the main solutions consisted of the constructive choices presented in Fig. 3.

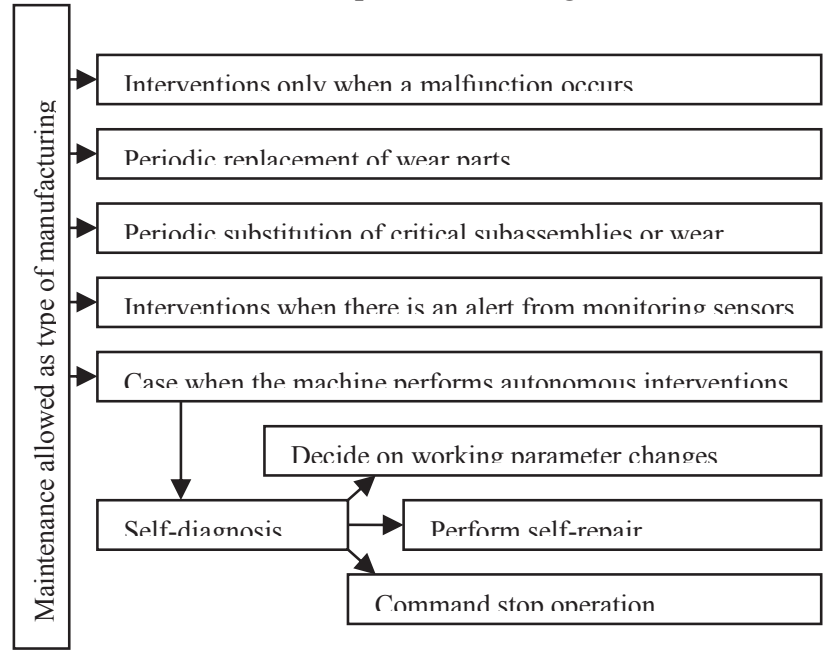

Fig. 3. Type of maintenance interventions

From the mistakes of the industrial past, from the needs of today's manufacturing industry, from the accumulations of theoreticians, researchers and practitioners in the field, the future directions of R \& D in the field of maintenance were outlined:

- The key issue that needs to be overcome in order to achieve the full potential of unmanned machining centers (but, we say, also for self-diagnosis and self-maintenance) is the development of reliable and effective sensors for monitoring machine operation, ensuring efficient metal removal rates and taking corrective action in the event of accidents or breakages ;

- Machines should include dimensional and proximity sensors to dimension and geometric corrections, cutting force sensor, spindle force and power load sensors, torque sensor and speed sensor to monitoring tool wear and tool breakage, acoustic emission sensors to monitoring entire manufacturing process [7];

- Use of intelligent maintenance systems to monitor, diagnose and predict the health of machines and their integrated components. Interfaces that mix the virtual reality can provide valuable support to maintenance operators to isolate and repair components of the equipment that might fail. The decision will be based on the analysis of the degradation behaviours of these components. The advantages of such a way of working consist in reducing maintenance time and costs caused by unpredictable failures of critical industrial equipment, where failures can seriously compromise the production process. For example, an interface that combines real and virtual using mixed/augmented reality techniques [8] has already been tested to facilitate replacement of spare parts $[9,10]$, as well as for technical inspections or repair [11, 12]. Using reality mixed with virtual in maintenance is not new $[13 \div 15]$, although previous research works do not deal with how to manage maintenance information or what data it needs to be presented;

- Diagnostic interface design have major implications on: complete redesign of the troubleshooting approach so as to allow for a smooth transition from failure mode to the failure cause, rethinking the reasoning behind which fault/damage messages are displayed, the maintenance operator will be fully immersed in the troubleshooting process, being in fact an active part of the local or remote computer system managing the diagnostic process of the manufacturing systems;

- Embedding in the construction of device fabrication systems such as sensors, embedded systems and computing devices have given a level of intelligence to system maintenance. This has led to a change from "fail and fix" to "anticipate and prevent" approach. This has irreversibly transformed future maintenance strategies [13] with regard to the complexity and uncertainty of the equipment, the trends being linked to new maintenance management methods such as resilient systems and selfmaintenance systems that are able to cope more good debris - base for developing these solutions as a CBM (Control Bazed Maintenance) paradigm [14]. Such systems, based on the CBM, have an information system [15] that acquires, stores and processes the information provided by a multitude of different sensors to monitor the state of operation of the production machines [16,17] - - several standards (e.g. ISO-13374 for Condition Monitory and Diagnostics of Machines [18], which provides a specification for information flow and data processing for monitoring and diagnosis of equipment health) were developed to assist engineers in the development of platforms and architectures to implement $\mathrm{CBM}$ on the factory floor (see a complete review of the state of the art, concepts, standards and platforms for maintenance in [19].

\section{Conclusions}

An overview of the evolution of tandem means of production - efficient maintenance techniques is presented in this study. Conventional and relevant modern methods used in the largest industrial sectors of the aeronautical industry, automotive industry, etc., have begun to provide information on the effectiveness of implementing artificial intelligence and electronic communication techniques in predictive maintenance.

Today's maintenance function is focused on emaintenance solutions, considering artificial intelligence techniques for decision-making, appropriate work patterns, and accentuating collaborative phenomena that are becoming more and more prevalent in manufacturing firms through systems distributed. The emphasis in the paper, whether positive or poor, is based on practical 
experience and provides recommendations for the further development of research in areas such as machine tools, sensors, monitoring and diagnostics, decision-making techniques with embedded AI, e-maintenance strategies with self-diagnosis and self-maintenance. Regardless of what is missing at the moment or is still inappropriately done, the potential of these techniques could be implemented through integration between data from multiple processing subsystems is huge.

From the point of view of practical implications:

- Self-diagnosis and self-maintenance are not a panacea. However, it is a concept of significant potential value, providing ways for businesses to exploit production activities with minimum wastage of materials, energy, human strength and time. Unfortunately, so far there have been few practical achievements that can be used to help students and practitioners alike.

From the point of view of originality

- This paper provides a useful insight into machine tools viewed from the point of view of its maintenance and an approach on which to base more in-depth research on the broader subject of the competitive strategy based on the compatibility of manufacturing systems with IT and AI techniques offered by results in related research fields. Based on the deployment of the faulty condition and related equipment information from the maintenance system, the visualization interface will be able to suggest/plan the repair/recovery solution. In this way, a computer-aided diagnostic system is supported by the interface which should be more intuitive interface and non-invasive for maintenance operator which must have mobility and free hands to perform the needed maintenance operations.

\section{References}

1. K.G. Swift, J.D. Booker, Manufacturing process selection handbook: from design to manufacture. Waltham, MA, USA: Butterworth-Heinemann, p. 456, 2013.

2. S. Kalpakjian, S.R., Schmid, Manufacturing engineering and technology. NewYork, Toronto, Prentice Hall, 2010.

3. Z. Zhu, V.G., Dhokia, A. Nassehi, S.T. Newman, $A$ review of hybrid manufacturing processes-state of the art and future perspectives. Int $\mathrm{J}$ Comput Integr Manuf, 26 (Feb (7)), pp. 596 $\div 615,2013$

4. D. Espındola, L. Fumagalli, M. Garetti, C.E. Pereira, S.S.C. Botelho, R.V. Henriques, A model-based approach for data integration to improve maintenance management by mixed reality, Computers in Industry 64, pp. 376 $\div 391$ (2013)

5. B. Esmaeiliana, S. Behdadb, B. Wang, The evolution and future of manufacturing: A review, JMS 39, pp. $79 \div 100$ (2016)

6. L. Fumagalli, D. Elefante, M. Macchi, B. Iung, Evaluating the role of maintenancematurity in adoption of new ICT in the process industry, in: In IMS'08: 9th IFAC Workshop on IMS, Szczecin, Poland, October 9-10, 2008, (2008)
7. J.Tlusty, G.C.Andrews, A Critical Review of Sensors for Unmanned Machining, CIRP Annals, Volume 32, Issue 2, pp. 563 $\div 572$, (1983)

8. P. Milgram, F. Kishino, A taxonomy of mixed reality visual displays, in: IEICE Transactions on I.S., vol. E77-D, No. 12, December, (1994)

9. H. Regenbrecht, G. Baratoff, W. Wilke, Augmented Reality Projects in the Automotive and Aerospace Industries, Published by the IEEE Computer Society, IEEE, November, (0272-1716 / 05, (2005).

10. S. Henderson, S. Feiner, Evaluating the benefits of augmented reality for task localization in maintenance of an armored personnel carrier turret, in: IEEE International Symposium on Mixed and Augmented Reality 2009, ST Proceedings, (2009)

11. S. Henderson, S. Feiner, Opportunistic tangible user interfaces for augmented reality, IEEE Transactions on Visualization and Computer Graph. 16 (1) (2010)

12. J. Song, Q. Jia, H. Sun, X. Gao, Study on the perception mechanism and method of virtual and real objects in augmented reality assembly environment, in: The 5th IEEE Conference on Industrial Electronics and Applications, (2009)

13. J. Lee, Design of self-maintenance and engineering immune systems for smarter machines and manufacturing systems, Invited Keynote Paper for IMS 2010, Lisbon, Portugal, July (2010)

14. M. Lebold, M. Thurston, Open standards for condition-based maintenance and prognostic system, in: Proceedings of MARCON $2001-5^{\text {th }}$ Annual MRC, Gatlinburg, USA, (2001)

15. L. Fumagalli, M. Macchi, M. Rapaccini, Computerized maintenance management systems in SMEs: a survey in Italy and some remarks for the implementation of Condition Based Maintenance, in: IFAC Proceedings Volumes (IFAC-Papers Online), vol. 13, Issue Part 1, 13th IFAC Symposium INCOM'09, Moscow June 3-5, pp. 1615-1619, (2009)

16. J. Lee, J. Ni, Infotronics-based intelligent maintenance system and its impacts to closed-loop product life cycle systems, in: Invited Keynote Paper for IMS'2004, Arles, France, (2004)

17. J. Lee, L. Liao, E. Lapira, J. Ni, L. Li, Informatics platform for designing and deploying $e$ manufacturing systems, in: Collaborative Design and Planning for Digital Manufacturing,, pp.1-35, (2009)

18. ISO, 13374 - International Organization for Standardization ISO 13374-1: condition monitoring and diagnostics of machines: data processing, communication and presentation, Part 1: general guidelines, Geneva, (2003)

19. A. Muller, A.M. Crespo, B. Iung, On the concept of e-maintenance: review and current research, in: Engineering and System Safety, Elsevier, http://dx.doi.org/10.1016/j.ress.2007.08.006, pp. $1165 \div 1187(2007)$ 